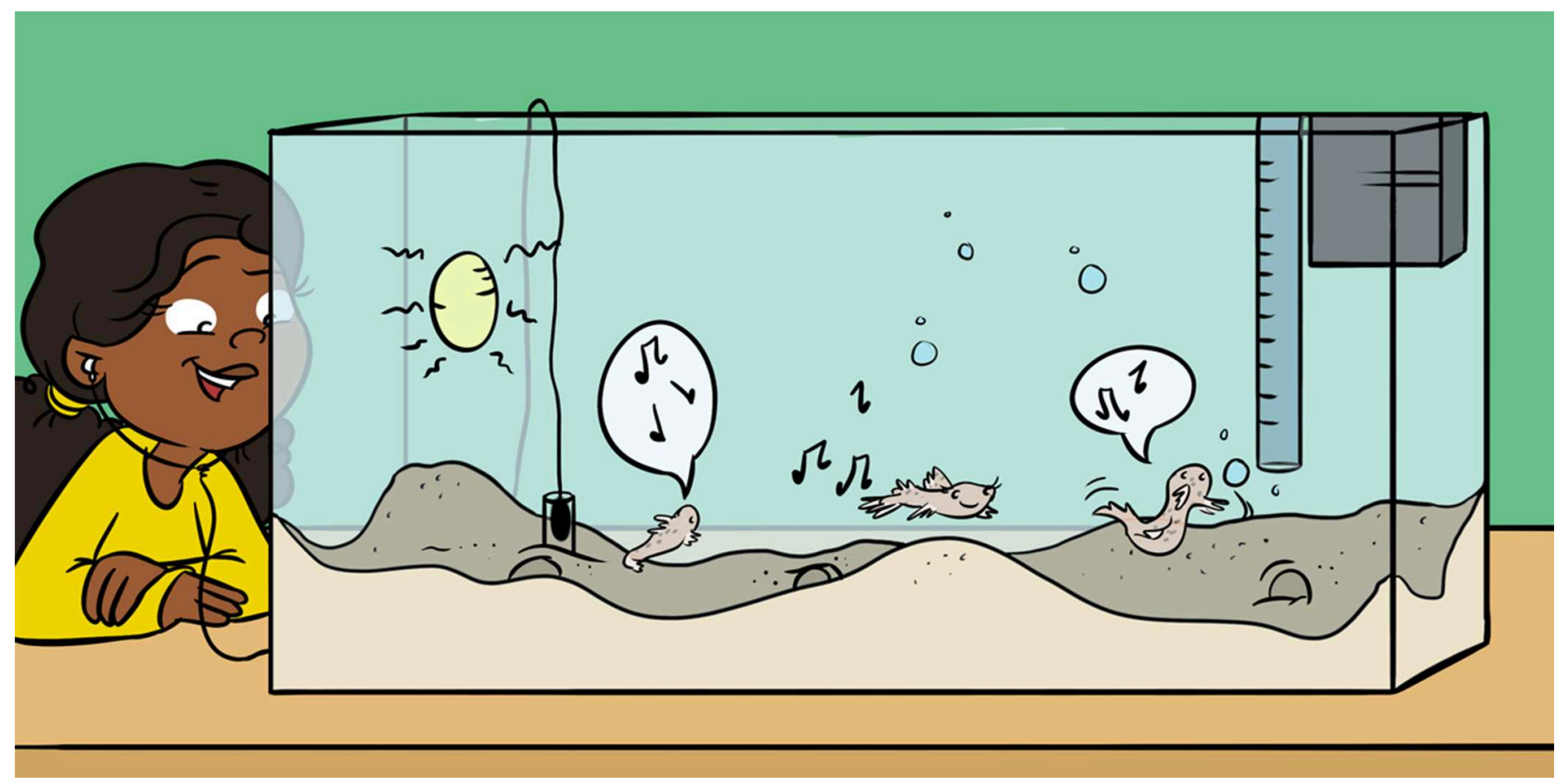

\title{
SINGING AND DANCING FISH: FEMALES PAY MORE ATTENTION TO MALES' DANCE MOVES WHEN IT IS NOISY
}

\author{
Karen de Jong ${ }^{1 *}$, Maria Clara P. Amorim ${ }^{2,3}$, Paulo J. Fonseca ${ }^{4}$ and Katja U. Heubel ${ }^{5,6^{*}}$ \\ ${ }^{1}$ Institute of Marine Research/Havforskningsinstituttet, Bergen, Norway \\ ${ }^{2}$ MARE-Marine and Environmental Sciences Centre, ISPA-Instituto Universitário, Lisbon, Portugal \\ ${ }^{3}$ Departamento de Biologia Animal, Faculdade de Ciências, Universidade de Lisboa, Lisbon, Portugal \\ ${ }^{4}$ Departamento de Biologia Animal, Faculdade de Ciências, cE3c-Centre for Ecology, Evolution and Environmental Changes, \\ Universidade de Lisboa, Lisbon, Portugal \\ ${ }^{5}$ Ecological Research Station Rees, Institute for Zoology, University of Cologne, Cologne, Germany \\ ${ }^{6}$ Research and Technology Centre (FTZ), Kiel University, Büsum, Germany
}

\section{YOUNG REVIEWER:}

FRANCISCO

AGE: 10
Just like humans, animals use signals to communicate with each other. For example, many male birds sing and dance to attract females. But what you may not know is that many fish do the same when they are fighting or mating. Unfortunately, humans are making a lot of noise in the ocean, which can disturb animal communication. There are many examples of this noise, such as boat traffic, wind farms, and oil platforms. We studied the effect of noise in a small marine fish species, the painted goby. Male gobies build nests under small shells and "sing" and "dance" to attract females to lay eggs in their nests. Females choose males mainly based on their song, but when it is noisy, females increase the amount of attention they pay to the male's dance moves when they are picking a partner. 


\section{HOW DO ANIMALS COMMUNICATE IN A NOISY ENVIRONMENT?}

Just like humans, animals use signals to communicate with each other. Communication (sending and receiving signals) can be disturbed by the environment. If this happens, it is possible that the intended receiver does not understand the message contained in the signal or does not notice the signal at all. You can compare this to when you shout to attract the attention of a friend across the street, but it is rush hour and he or she does not hear you through the traffic.

Humans are making a lot of noise in the ocean, for example by boat traffic and from large industrial plants, such as wind farms and oil platforms. This noise can disturb animal communication. Because communication is very important for animals, disruption of communication can change their lives. For instance, female frogs cannot hear males calling when traffic noise gets too loud. This may lead to situations in which females cannot find mates or cannot distinguish between different types of males. To solve this problem, many animals use more than one type of signal to get a message across-just like you do when you wave to attract the attention of your friend across the street who did not hear you when you shouted.

Just as you may want to shout louder and wave with your whole arm rather than just with your hand when you try to communicate with your friend across a busy street, animals may sing louder or longer or start using body movements to catch their communication partners' attention in noisy circumstances. However, whether or not the receiver (your friend) is actually paying attention to your arm-waving or just keeps trying to listen to what you are shouting is something you do not know.

MATE

Producing offspring together: in painted gobies, females lay eggs in a nest and males fertilize the eggs with sperm. After mating, the father takes care of the eggs until they hatch.

\section{DUMB AS A FISH}

Just because they cannot speak like humans do, does not mean that fish cannot communicate using sound. Most fish listen to their environment and many fish produce sounds for communication. Fish can use sound to communicate with shoal members, to tell rivals how strong they are, and to tell potential mates that they want to mate.

Unfortunately, a lot of the noise humans make underwater has frequencies similar to the fish songs. To understand how noise affects fish, we studied a sound-producing fish, the painted goby (Pomatoschistus pictus). Painted goby males sing and dance to attract females to their nests, but females usually pay more attention to the males' song than to the males' dance moves when they are choosing a mate [1]. For females, it is especially important to choose a healthy and 
Figure 1

Setup of the

experiment to test the effects of noise on fish communication. The "noise egg" was placed behind the male in his nest (a plastic tube). Most males covered the nest with sand. The hydrophone was placed in a specially made chimney on top of the nest, to record the sounds of the male inside the nest. Two females were moving freely in the aquarium (adapted from source article).

\section{COURTSHIP}

Acts to convince animals of the opposite sex to mate, such as dances or songs.

\section{CONDITION}

The weight of an animal compared to its size. Since a large animal will always be heavier than a small animal, the condition score is related to body size. Thus, if a large and a small animal weigh the same, the small animal will get a higher condition score than the larger animal.

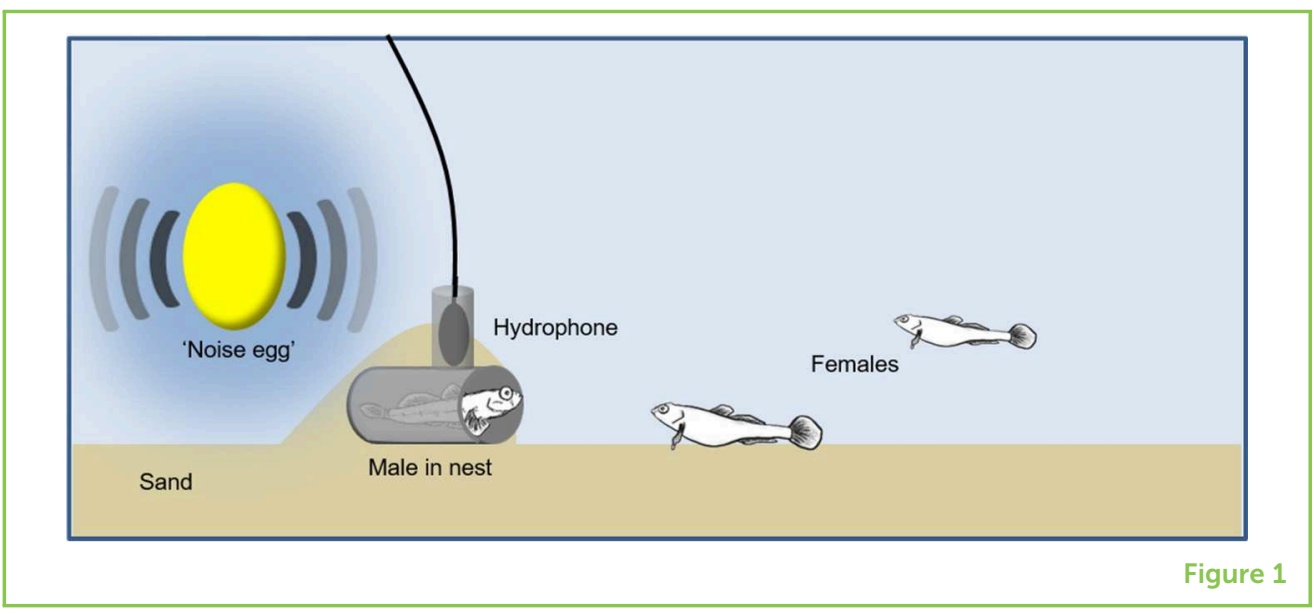

strong male. Those males will likely have healthy and strong children and will also take good care of their offspring. So, females have to choose a good male that is also going to be a good dad. Knowing that it is important for females to be choosy, we tested whether females start paying more attention to male dance moves when they meet in noisy circumstances, or if those females continue to search for other males.

\section{HOW DID WE STUDY THE EFFECT OF NOISE ON FISH COMMUNICATION?}

We studied fish mating behavior with experiments performed in aquaria. Each aquarium had one painted goby male with a nest and two females (Figure 1). Painted gobies communicate in two ways-acoustically, using two types of sound, and visually, using various movements like hopping, jumping, shaking and approaching other fish [2].

In 16 experiments the aquaria were silent and in 20 other experiments we played noise with a device we have named the "noise egg" [3]. From earlier studies, we knew that this artificial noise resembles human noise in the ocean [3]. We observed male acoustic and visual courtship behavior and checked how the females reacted and whether the males and females mated or not.

The painted gobies built nests in the aquaria by shoveling a pile of sand over plastic tubes (Figure 1). The males then guarded the nests and tried to attract the females. Using a video camera and an underwater microphone (called a hydrophone) we recorded both the "dance" moves and the sounds of the male. Later, we analyzed how male songs and dance moves were affected by the male's size and his body condition (how heavy they are for a given size). We then compared females' mating decisions in the noisy vs. the silent 
aquaria, to understand if females chose a male based on his sounds or his moves.

\section{NOISE AFFECTS THE WAY FISH COURTAND ACCEPT MATES}

In the aquaria with added noise, the fish communicated less. Both sounds and movements were produced less often [4]. In both silent and noisy aquaria, males that produced more sounds had higher chances of getting a female to lay eggs in their nests. But it was only in the noisy tanks that male dance moves became important for attracting a mate. Provided they danced a lot, even males that did not sing much had good chances of mating in the noisy tanks. Furthermore, the males that were in better condition, meaning they were heavier for the same size and produced more sounds and visual signals, were more likely to mate than males that were leaner and produced fewer sounds and visual signals.

\section{IT IS IMPORTANT TO COMMUNICATE USING MORE THAN ONE SIGNAL!}

To understand the relationship between a male painted goby's characteristics (including behavior) and his chance of mating in either silent or noisy conditions, we related the male's size, condition, song, and dance moves with the occurrence of mating (Figure 2).

We found that noise affects the relationship between male courtship behavior and female mating decisions. In silent tanks, males that sang more had more mating opportunities; however, in noisy tanks, the males that danced more were better at getting a female to mate. This means that female painted gobies pay more attention to visual courtship signals when noise disturbs acoustic communication.

The information collected from our experiment tells us that fish that use more than one method of signaling have a better chance of being able to communicate under different circumstances. Communicating by more than one method provides a back-up to protect against information loss. If the environment disturbs one communication signal, the other signal becomes more important for both the sender (in our case, the male) and the receiver (the female) [5]. In noisy conditions, we would expect that males would switch from singing to dancing, if dancing becomes more important for communicating with females. Surprisingly, we did not find that the males in noisy tanks danced more than the males in silent tanks. However, females did pay more attention to the males' dance moves in the noisy tanks. A similar result was also found in another fish, the three-spined stickleback (Gasterosteus aculeatus). Stickleback males danced more in cloudy water, but females paid more attention to scent [6]. 


\section{Figure 2}

We found relationships between the males' characteristics (size and condition), courtship behavior (song and dance moves), and likelihood of mating. These relationships are shown with arrows: gray, thin arrows for non-significant optional relationships and green, thick arrows for significant positive relationships. The relevant male behaviors leading to mating in (A) silent and (B) noisy aquaria are shown with drawings and green arrows. Fish drawings show a dancing male, a singing male, and a female ready to mate (adapted from source article).

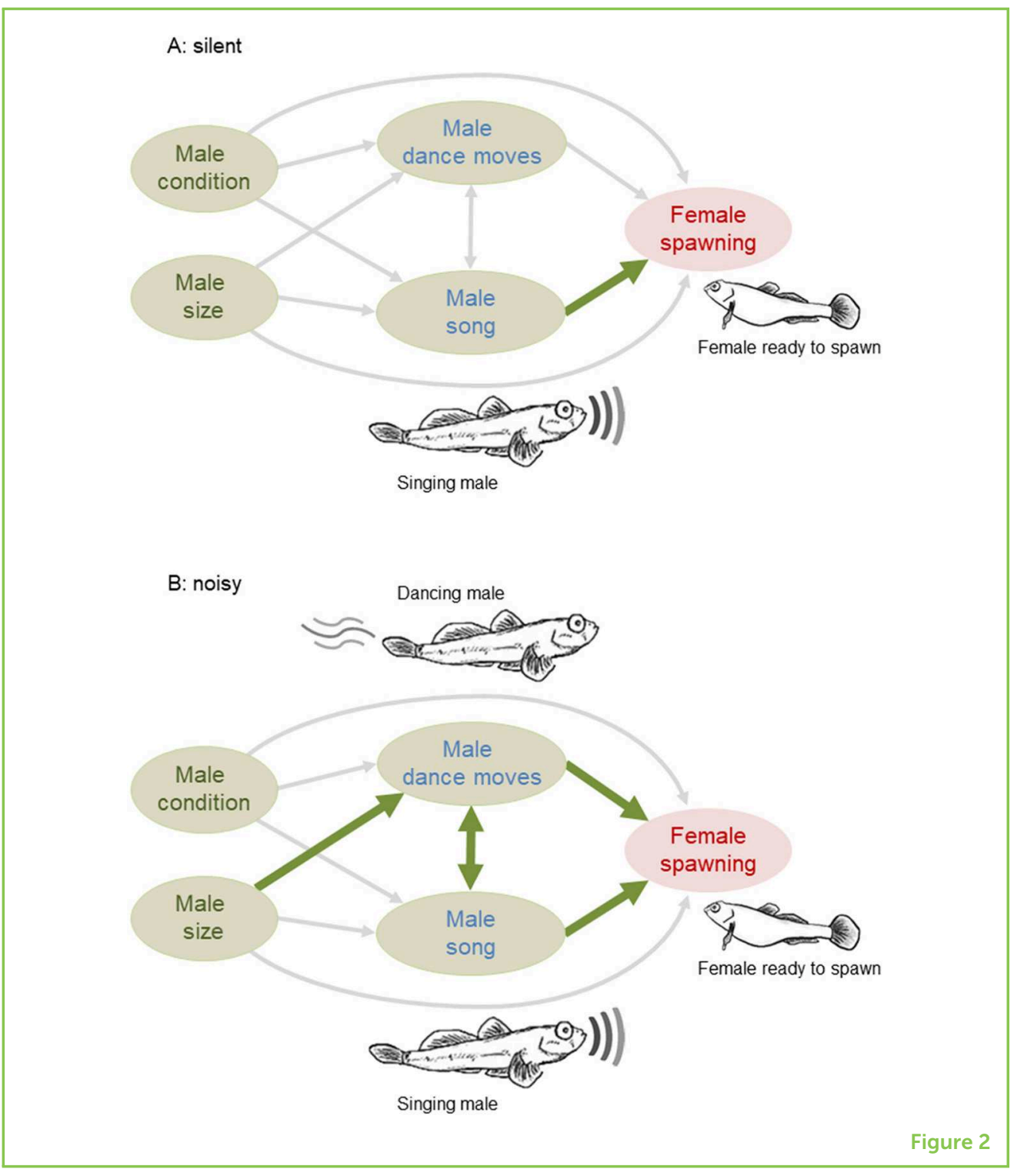

\section{CONCLUSION}

We found that, in noisy tanks, the male painted gobies sang less, the females paid more attention to the males' dance moves, and males that sang less had a better chance of mating if they danced. If females choose silent males to mate with, they may produce children that do not sing either. Over time, this could mean that if the world becomes noisier due to human activities, painted gobies may become "as dumb as a fish" after all.

\section{AUTHOR CONTRIBUTIONS}

$\mathrm{KJ}$ and $\mathrm{KH}$ designed the experiment, with comments from MA and PF. $\mathrm{KJ}$ executed the experiment and analyzed the data. $\mathrm{KJ}$ and $\mathrm{KH}$ wrote the manuscript with comments and revisions by MA and PF. 


\section{ACKNOWLEDGMENTS}

We would like to thank the University of Lisbon for providing laboratory space. Maria Gouveia, Catarina Rosa, and Joana Vicente for help with catching, husbandry, and logistics. We would like to thank Adrian Klein for kindly providing us with particle motion sensors and help with the analyses of the PM-data. We thank Kalle de Jong for help with figure design and Liisa Ylitepsa for the original drawings of gobies.

\section{ORIGINAL SOURCE ARTICLE}

de Jong, K., Amorim, M. C. P., Fonseca, P. J., and Heubel, K. U. 2018. Noise affects multimodal communication during courtship in a marine fish. Front. Ecol. Evol. 6:113. doi: 10.3389/fevo.2018.00113

\section{REFERENCES}

1. Amorim, M. C. P., Pedroso, S. S., Bolgan, M., Jordão, J. M., Caiano, M., and Fonseca, P. J. 2013. Painted gobies sing their quality out loud: acoustic rather than visual signals advertise male quality and contribute to mating success. Funct. Ecol. 27:289-98. doi: 10.1111/1365-2435.12032

2. Amorim, M., and Neves, A. 2007. Acoustic signaling during courtship in the painted goby, Pomatoschistus pictus. J. Mar. Biol. Assoc. U.K. 87:1017-23. doi: 10.1017/s0025315407056822

3. de Jong, K., Schulte, G., and Heubel, K. U. 2017. The noise egg: a cheap and simple device to produce low-frequency underwater noise for laboratory and field experiments. Methods Ecol. Evol. 8:268-74. doi: 10.1111/2041-210X.12653

4. de Jong, K., Amorim, M. C. P., Fonseca, P. J., Fox, C. J., and Heubel, K. U. 2018. Noise can affect acoustic communication and subsequent spawning success in fish. Environ. Pollut. 237:814-23. doi: 10.1016/j.envpol.2017.11.003

5. Partan, S. R. 2017. Multimodal shifts in noise: switching channels to communicate through rapid environmental change. Anim. Behav. 124:325-37. doi: 10.1016/j.anbehav.2016.08.003

6. Heuschele, J., Mannerla, M., Gienapp, P., and Candolin, U. 2009. Environment-dependent use of mate choice cues in sticklebacks. Behav. Ecol. 20:1223-7. doi: 10.1093/beheco/arp123

SUBMITTED: 26 March 2019; ACCEPTED: 13 August 2019; PUBLISHED ONLINE: 04 September 2019.

EDITED BY: Pedro Morais, Centre of Marine Sciences, University of Algarve, Portugal

CITATION: de Jong K, Amorim MCP, Fonseca PJ and Heubel KU (2019) Singing and Dancing Fish: Females Pay More Attention to Males' Dance Moves When It Is Noisy. Front. Young Minds 7:110. doi: 10.3389/frym.2019.00110 


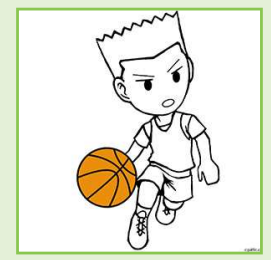

CONFLICT OF INTEREST STATEMENT: The authors declare that the research was conducted in the absence of any commercial or financial relationships that could be construed as a potential conflict of interest.

COPYRIGHT @ 2019 de Jong, Amorim, Fonseca and Heubel. This is an open-access article distributed under the terms of the Creative Commons Attribution License (CC BY). The use, distribution or reproduction in other forums is permitted, provided the original author(s) and the copyright owner(s) are credited and that the original publication in this journal is cited, in accordance with accepted academic practice. No use, distribution or reproduction is permitted which does not comply with these terms.

\section{YOUNG REVIEWER}

\section{FRANCISCO, AGE: 10}

I am 10 years old, I live in Barcelos (north of Portugal). I am very curious about everything and science is one of my interests. What I love the most is to play basketball.

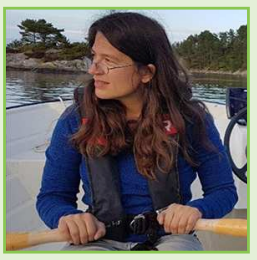

\section{AUTHORS}

\section{KAREN DE JONG}

The first time I became interested in fish sounds was during my M.Sc. thesis, when I recorded the sounds produced by the Azorean rock-pool blenny on the Azores. After that, I focused on how the environment can affect fish behavior and fish reproduction. Now, I combine these interests to study the effect of human-made noise on fish mating behavior, mainly in sound-producing fish. I worked in Norway, the Netherlands, and Germany, and am now living in Bergen, Norway, with my husband and two children. *karen.de.jong@hi.no; karende@alumni.ntnu.no

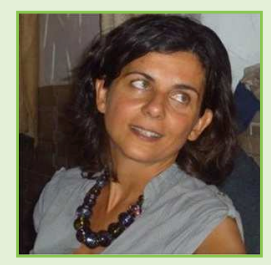

\section{MARIA CLARA P. AMORIM}

I graduated in Biology from the University of Lisbon (1991), completed an M.Phil. degree at the University of Leicester (1994) on fish foraging behavior and received a Ph.D. degree from the University of Aberdeen (1997) on acoustic communication in fish. After my Ph.D. I returned to Portugal and continued to study acoustic communication in fish, focusing on how acoustic signals mediate social interactions. Recently, I have begun to address the impact of human noise in the ocean, including its effects on fish fitness and vocal communication.

\section{PAULO J. FONSECA}

For about 25 years I worked on sound communication in cicadas, mainly with field work performed in Portugal and lab work in Germany, Denmark, and Portugal. I tried to understand how cicadas produce and radiate their sounds and how the hearing system can perceive these sounds, leading to finding mates. In 2003, I became interested in fish acoustic communication, the culprit being Maria Clara Amorim. Since then, we have used several fish models to approach questions related to sound production and hearing, the role of sounds mediating aggressive and sexual (mate attraction and selection) interactions, and the effect of man-made noise on fish 


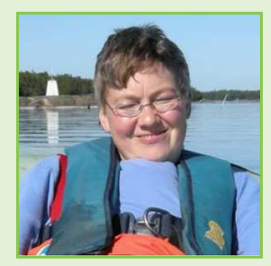

communication and stress. Recently, I got interested in the underwater acoustics of tropical reefs as a tool for management and conservation.

\section{KATJA U. HEUBEL}

When I started studying biology in Germany and Denmark, I was mainly interested in insect ecology and behavior. Later, doing my doctoral studies, I did field work in Texas and Mexico because I became fascinated by the question of how sexual and asexual fish can coexist. This question is hard to answer. This is why I also spent a couple of years in Finland trying to explain this. In the past years, I became interested in how native and invasive fish in the Baltic Sea adjust their lifestyles to different environmental conditions, social contexts, or communities. *heubelaftz-west.uni-kiel.de 